Leitura, n. 21 - Sala de Aula de Lingua, p. 125-143, jan./jun. 1998

\title{
A CONSTRUÇÃO DO CONHECIMENTO NA SALA DE AULA : ESTRATÉGIAS DISCURSIVAS DO PROFESSOR
}

\author{
M. Bernadete F. de Oliveira \\ Programa de Pós-Graduação em Estudos da Linguagem \\ Universidade Federal do Rio Grande do Norte
}

\section{INTRODUÇÃO}

A tese de que os processos cognitivos superiores se realizam através de relações interpessoais, pela mediação de outros sujeitos - pessoas físicas, objetos, signos -, construindo significados que impregnam os elementos do mundo cultural, vem sendo confirmada nas pesquisas que se fundamentam nos postulados teóricos do paradigma sócio-histórico, que encontra em Vygotsky e seguidores seus melhores representantes.

De outro lado, intensificam-se também as pesquisas que investigam o cotidiano da escola e seu papel no processo de apropriação do saber, principalmente, com o objetivo de procurar novos caminhos que apontem para uma educação de qualidade permitindo enfrentar os desafios colocados pela contemporaneidade e seus avanços tecnológicos, ultrapassando as pesquisas que se limitam ao diagnóstico das causas do fracasso escolar.

No bojo desta temática, assume relevância investigar a contribuição da linguagem nos processos de apropriação e elaboração do conhecimento, que se realizam no âmbito da instituição escolar, considerando seu funcionamento ao mesmo tempo como objeto e agente destes mesmos processos. Entendemos que o conhecimento escolar insere-se na modalidade do conhecimento cientifico, o qual segundo Bunge (1973, p.64) " ..é inteiramente conceitual...", ou seja, compõe- 
se de conceitos, unidade do pensamento, inter-relacionados de diversas formas e envoltos em signos. É um conhecimento sistematizado, que busca hipóteses explicativas, testáveis, sendo suas conclusões resultantes da aplicação de procedimentos metodológicos definidos (Nagel, 1974). Nessa mesma direção, Lefebvre (1970) afirma que é através dos signos que se processa o acesso a este tipo de conhecimento. Em resumo, pode-se entender o conhecimento científico como aquele que se apresenta estruturado sob a forma de conceitos, proposições e teorias. São os conhecimentos organizados pelas diferentes disciplinas nos diversos campos do saber, em cujo processo de produção, apropriação e divulgação, a linguagem verbal assume papel relevante.

O conhecimento escolar, portanto, situar-se-ia no campo do conhecimento científico, na medida em que é papel essencial e função social da escola ser o espaço institucional de produção e transmissão do saber sistematizado. Como diz Fourquin (1993), a escola é responsável pela "transmissão cultural" de conhecimentos, competências, crenças, hábitos, valores, ou seja, aquilo que se convencionou denominar de conteúdo da educação. Deste ponto de vista, o conhecimento escolar caracterizar-se-ia por assumir a forma de um conhecimento sistematizado, elaborado, e organizado de apropriação e construção do real, contendo uma determinada visão de mundo, o que no campo da investigação científica implicaria pressupostos epistemológicos tanto sobre as relações entre o homem e o processo de apreensão da realidade, quanto sobre a natureza desta realidade.

Compreender a relação entre estes dois tipos de conhecimento e suas origens - de um lado o processo do conhecimento científico, centrado na apropriação do conhecimento acumulado historicamente e representado através dos avanços da ciência: e de outro o processo de conhecimento espontâneo, que obedece a outra lógica, a outros procedimentos, mas nem por isso assistemáticos - deve ser objeto dos conteúdos curriculares dos cursos de formaçäo de professores.

Na busca de contribuir para a compreensão do papel da linguagem no processo de construção do conhecimento no 
âmbito da instituição escolar, este artigo apresenta resultados de uma pesquisa, cujo objetivo principal centrou-se no processo ensino e aprendizagem na instituição escolar, mais especificamente na investigação dos elementos presentes no discurso da escola, através de seus agentes preferenciais professores e alunos. Pretendemos investigar como se constrói o conhecimento no contexto da sala de aula, considerando, de antemão, este processo como uma prática social mediada pela palavra e pelo outro. A observação de como se processa a negociação de sentidos entre professor e alunos, e a forma como o professor articula os conhecimentos dos alunos em seu sistema de explicação são aspectos fundamentais para que se entenda a dinâmica de construção do conhecimento em sala de aula.

\section{A SALA DE AULA E A CONSTRUÇÃO DO CONHECIMENTO}

Cole (1990) considera que, no nível das pesquisas microgenéticas, as análises da interação ensino/aprendizagem em salas de aula delineiam um quadro de similaridades muito amplo, modificado, até certo ponto, por práticas locais. As escolas de hoje, diz ele, apresentam características já presentes na antiga Suméria como, por exemplo, o uso de sistemas simbólicos escritos como instrumentos específicos de mediação, no processo de escolarização formal. Ainda segundo este autor, as conseqüências da escolarização se fazem presentes, quanto à informação estruturada de acordo tanto com as categorias que fazem parte da tradição que criou a ciência moderna quanto com as instituições burocráticas, conseqüências estas evidenciadas nas crianças escolarizadas através de seu desempenho nas tarefas, entre as quais salientem-se aquelas de memorização e de classificação. Um outro aspecto da escolarização que merece destaque, segundo aquele autor, diz respeito à estrutura participativa de seus agentes preferenciais - professores e alunos -, e a forma do discurso através da qual esta participação se processa. Ou seja, na escola, a aprendizagem é dirigida para o domínio de objetivos definidos e o padrão de linguagem utilizado pode ser definido como "discurso instrucional", que, diferindo em estrutura e conteúdo de outras formas de discurso, tem como 
objetivo dar informações às crianças sobre o conteúdo do currículo e feedback a seus esforços, ao mesmo tempo que fornece aos professores informações sobre o progresso dos alunos. Um dos indicadores deste tipo de discurso é a presença da seqüência introdução-resposta-avaliação. O professor pergunta, o aluno responde, o professor fornece sua avaliação. O discurso instrucional pergunta sobre o que a criança sabe, e ensina a responder questões cujas respostas já são conhecidas por parte de quem pergunta. Esta é uma primeira lição importante da escolarização.

Moll (1990), ao tratar da escola - instituição que segundo ele tem como finalidade particular a "organização social da instrução" - afirma que o discurso escolarizado representa uma forma de comunicação qualitativamente diferenciada porque as palavras agem não apenas como meio de comunicação como no discurso cotidiano, mas também como objeto de estudo. Nas interações em sala de aula, o professor dirige a atenção das crianças para os significados e definições da palavra, bem como para as relações sistemáticas entre elas, na construção de um sistema organizado de
conhecimento.

Segundo Bernstein (1990), o discurso pedagógico pode ser definido como um processo que, além de transformar um discurso de competência, em um discurso de ordem, de tal forma que o último sempre domine o primeiro, reflete habilidade de vários tipos. O referido autor, além disso, entende que o discurso pedagógico vem a ser a junção de um competências especializadas e suas inter-relações, com um discurso de regulação, definido em termos de principios ativos dos quais as relações sociais de transmissão e aquisição do conhecimento são constituídas, mantidas, reproduzidas $e$ legitimadas. Dessa forma, para ele, o discurso pedagógico não tem um discurso próprio, constituindo-se em princípios recontextualizadores, em função das relações escola e sociedade e da organização interna da própria instituição escolar.' O discurso de uma área do conhecimento é deslocado de seu campo original e realocado na escola por meio de recontextualizações sucessivas, ou seja, o que Fourquin(1993) 
chama de transposição didática, o processo de transformação da produção artística, literária ou científica em conhecimento escolar. Mas é necessário advertir que, tanto para Bernstein como para Fourquin, o conhecimento escolar não deve ser entendido necessariamente como uma simplificação ou redução do conhecimento produzido no âmbito das diversas áreas do conhecimento. Pelo contrário, é necessário fazer uma distinção entre o conhecimento necessário ao professor para realizar sua atividade docente, e aquele que deve ser apropriado pelo aluno.

\section{A SALA DE AULA E A INTERAÇÃO VERBAL}

As pesquisas sobre os processos interacionais na relação ensino/aprendizagem vêm dedicando bastante espaço ao estudo do discurso da (e na) sala de aula. De acordo com Smolka (1991), estas pesquisas podem ser agrupadas em função do paradigma científico adotado. A primeira delas diz respeito aos estudos empíricos que analisam as interações inter ou intra pares, em uma abordagem marcadamente cognitivista; em seguida, têm-se os estudos desenvolvidos por antropólogos, etno-metodólogos, sociolingüistas, que buscam compreender as formas de organização do comportamento em sala de aula, geralmente em observações naturalistas; outros, de natureza teórica, exploram a relação escola/sociedade, em geral, com base em tendências marxistas, enfatizando as relações de poder; por último, têm-se aqueles que procuram trabalhar o empírico e o teórico, no contexto educacional, articulando as dimensões micro(cotidiano) e macro(relações estruturais e funcionais) da instituição escolar.

Kleiman (1991) também apresenta sua visão das vertentes que estudam a interação verbal. Para ela, tais pesquisas poderiam ser agrupadas em dois grupos: de um lado, os que analisam como as relações sociais estabelecidas entre os interlocutores em sala de aula estão refletidas no produto desse diálogo e que tipos de estruturas elas configuram; de outro, aqueles que se ocupam com o processo comunicativo que institui "contextos de aprendizagem". 
De nosso ponto de vista, o conceito de interação remete a toda ação conjunta, conflitual e/ou cooperativa, realizada entre dois sujeitos, e nesse sentido, concordamos com Brait, quando esta afirma que "a interação verbal é um componente do processo de comunicação, de significação, de construção de sentido e que faz parte de todo ato da linguagem. É um fenômeno sociocultural, com caracteristicas lingüísticas e discursivas passiveis de serem observadas, descritas, analisadas e interpretadas" (Brait,1995,p.194).

Este mesmo conceito é adotado por diversos autores no âmbito de estudos filosóficos da linguagem. Habermas (1987), por exemplo, estuda a função comunicativa da linguagem e seu funcionamento nas situações interativas. Este autor distingue entre a ação comunicativa - aquela orientada para a intercompreensão entre os sujeitos - e a ação instrumental, orientada apenas para a obtenção dos objetivos de cada interlocutor individualmente. Segundo ele, o agir comunicativo pressupõe um tipo de racionalidade, ou, no seu dizer, uma "razão comunicativa", que apenas se realiza quando os interlocutores têm a autonomia cognitiva e moral, seja de ação, seja de pensamento, o que não significa dizer que eles não possam estar limitados por qualquer outra forma de imposição ou repressão, que não a obediência às regras estabelecidas entre eles próprios, interessados diretamente no processo.

No caso específico da instituição escolar e do papel da linguagem no processo de apropriação do saber, pode-se interpretar que a transmissão desse saber deve se processar em uma situação na qual os interlocutores venham participar em igualdade de condições, isto é, que os sujeitos venham a respeitar o conjunto de princípios estabelecidos anteriormente, de forma consensual. É desta maneira que, no âmbito de uma razão comunicativa e não instrumental, pode ser pensada, de uma forma concreta, a heterogeneidade dos papéis de
professores e alunos.

No âmbito dos estudos lingüísticos, Bakhtin (1929) atribui um funcionamento dialógico ao signo verbal, permitindo a recuperação da função comunicativa da linguagem, em sua plenitude. A dialogia de Bahktin está ancorada em dois pilares básicos, quais sejam na afirmação de que os signos "só podem 
aparecer em um terreno interindividual..." (Bahktin, 1929, p.35), e na instauração do outro no processo discursivo, ou, no seu dizer, "a palavra dirige-se a um interlocutor: ela é função da pessoa desse interlocutor..." (Bahktin, 1929, p.112).

Smolka (1991b), por exemplo, com base nesse Smolka (1991b), por exemplo,
referencial, estuda a dimensão discursiva - mediada pela
palavra - e a dimensão pedagógica - mediada pelo outro -, em uma sala de aula, de uma escola de primeiro grau, concluindo que as estratégias discursivas e pedagógicas utilizadas pela professora instauram as crianças como protagonistas do evento e não apenas como mera audiência, procedimento mais comum encontrado nas salas de aula, configurando-se desta forma, em seus dados, os princípios da dialogia. Seguindo esta mesma perspectiva e paradigma, Gabbiani (1991) estuda também as estratégias discursivas utilizadas pelos professores, na tríade - pergunta, resposta, avaliação -, concluindo na direção contrária àquela de Smolka, ou seja, as estratégias utilizadas pelos professores não contribuem para a ampliação dos conhecimentos dos alunos no sentido esperado. Em estudos empíricos, Kleiman (1992) também relaciona o uso de perguntas em sala de aula com a questão da transmissão de conhecimentos; segundo esta autora, as perguntas pedagógicas são exclusivas do discurso de sala de aula, ocorrendo em situações assimétricas e sendo sempre iniciadas pelo professor, que exerce o papel social de controle.

Esta nossa pesquisa priorizou o estudo das estratégias discursivas utilizadas pelo professor, em sala de aula, em eventos diferenciados, procurando investigar se essas estratégias possibilitam a negociação dos significados e sentidos entre professor e alunos, assim como a incorporação do conhecimento dos alunos ao seu sistema de explicação. Elegemos, como unidade de análise da comunicação verbal, o enunciado - unidade da comunicação verbal, produto da interação de dois indivíduos socialmente organizados, e que reflete as atividades humanas, através dos gêneros de discurso primários e secundários, possibilita o estudo das práticas discursivas (Bakhtin, 1952). 
O enunciado assim conceituado introduz a alteridade, ou, como já discutimos em artigo anterior (Oliveira, 1996), instaura o outro no processo discursivo, em duas dimensões, qual seja, o " outro", parceiro da comunicação, presente ou não fisicamente na situação de interação verbal, e "as vozes", os enunciados alheios que se infiltram nos nossos, manifestando suas idéias, visão de mundo, pontos de vista, e que no seu limite implicam a existência de um sistema de referência subjacente.

Para Bahktin (1952), esta instauração do outro provoca a "alternância dos sujeitos" no processo da comunicação, conferindo uma nova dimensão aos estudos do processo da significação, na medida em que o tu é dotado de uma compreensão responsiva ativa que implica a sua participação no processo da interação verbal. Ou dizendo em outras palavras, este outro é aquele que concorda ou discorda, completa ou adapta a fala de seu interlocutor, cumpre ou não as ordens da mensagem, ou mesmo cala, reflete e ignora, dai toda compreensão ser prenhe de resposta e pressupor a transformação do ouvinte em locutor, com uma atitude "responsiva ativa". Esta alternância de interlocutores, estabelecendo fronteiras nos enunciados, vai se constituir em elemento de caracterização do enunciado, para aquele autor.

Um outro elemento, importante para este nosso estudo, diz respeito ao outro "tu", presente na concepção dialógica daquele autor, representado nos enunciados pelas vozes alheias, as quais em função de sua multiplicidade de posições ideológicas, plenivalentes, manifestando pontos de vista diferenciados, podem caracterizar um discurso inserido no gênero de discurso primário ou secundário. Bakhtin considera que os gêneros secundários do discurso, entre os quais o discurso científico, aparecem em circunstâncias "...de uma comunicação cultural mais complexa e relativarnente mais evoluida..." (Bakhtin, 1952.p.281). Ainda segundo este autor, tais gêneros discursivos se formam pela absorção, seguida de uma transformação dos gêneros primários, os quais se constituem ao nível da comunicação verbal espontânea.

Neste estudo, cujo objeto principal centrou-se no estudo das estratégias discursivas utilizadas pelo professor em sala de 
aula, selecionamos como categorias de análise a "alternância dos sujeitos", pretende identificar as marcas discursivas do tipo de relação entre os participantes do evento pedagógico professores e alunos -, como são negociados os sentidos e como o professor incorpora o conhecimento espontâneo do aluno ao conhecimento sistematizado, ou seja, como ele considera seu interlocutor; além de pretender identificar também as vozes que se apresentam no discurso do professor e dos alunos, buscando identificar qual o gênero discursivo predominante.

\section{A SAla dE AULA E AS ESTRATÉgIAS DISCURSIVAS DO PROFESSOR}

Foram analisados três eventos, referindo-se o primeiro deles à atividade de descrever, oralmente, a representação gráfica que os alunos haviam realizado sobre o que eles entendiam dos conceitos de "município, cidade e bairro". No evento de número 2 , a professora retoma o conceito de "tempo", apresentado aos alunos em aula anterior, e realiza uma sessão de discussão, em grupo, para avaliar a compreensão desse conceito. E no evento de número 3 , a professora através do recurso de uma conversa informativa pretende, a partir da noção de tempo histórico, introduzir as noções de tempo verbal - presente e passado - e os tipos de texto - narração e descrição.

Os dados foram coletados, através de gravação, em uma turma de 2a. série do Primeiro Grau, em escola pública do Município de Natal. A transcrição não acompanhou a representação fonética. Os alunos, em um total de 28 , em sua maioria, são filhos de trabalhadores assalariados do setor público e/ou privado, com uma faixa salarial de até dois salários mínimos. A faixa etária variou entre 8 e 11 anos, com uma predominância do sexo feminino. A regência da classe estava a cargo de uma professora com $2^{\circ}$. Grau completo, aluna do Curso de Pedagogia da UFRN. 


\section{Evento 1}

Esse evento tem início com a professora indagando um dos alunos sobre a realização de tarefa solicitada anteriormente, qual seja, a de representar através de um desenho a compreensão do que seria "o municipio". Esta será a estratégia discursiva utilizada pela professora durante todo o evento, isto é, ela vai fazer uso do mesmo ato de linguagem, isto é, solicitar explicações aos alunos como nos exemplos, "explique seu trabalho", "agora, diga o que você fez", refletindo em seu discurso os padrões convencionais do discurso instrucional. Ao dirigir-se ao aluno, a professora estabelece o objeto do sentido, na terminologia de Bahktin, o "tema" do discurso, podendo-se mesmo afirmar que a professora instaura o outro e concede-Ihe a palavra, uma vez que a seqüência Pergunta / Resposta - embora não necessariamente na forma lingüistica tradicional de pergunta, está presente durante todo o evento. Em um primeiro momento, portanto, poderiamos afirmar que a professora fez uso de estratégias discursivas e práticas pedagógicas que levariam à instauração do diálogo. Contudo essa análise nos parece superficial. Vamos acompanhar um fragmento desse evento.

1 Prof. (dirigindo-se a um aluno)... Explique como fez o trabalho...

2 Aluno: Fiz casas, bairro e município, eu não sei explicar não

3 Aluno (outro): Desenhei um círculo, ai botei bairro, bairro, bairro.

A cidade é grande, tia a cidade está crescendo mais, tia, a cidade perdeu a zona rural, né tia?

4 Prof.(para outro aluno)... Explique seu trabalho

5 Aluno: Tia, fiz casas, carros, prédios, vacas, tudo isso tia é municipio...agora eu desenhei uma bola com o nome bairro Neopólis e Pirangi. Outra um pouco maior com a cidade de Natal...eu botei tia...Extremoz e Parnamirim....outra maior com municipio...isto tudo aqui (mostrando o desenho)...Mas tia, Extremoz e Parnamirim são outros municipios...

6 Aluno (outro): ... agora eu... desenhei uma bola com o nome do bairro Neopólis...outra maior a cidade do Natal...eu botei tia Extremoz e Parnamirim...isto tudo aqui tia (mostrando o desenho) 7 Aluno (o mesmo da linha 5)... mas tia, Extremoz e Parnamirim são outros municipios...

8 Profa ... Tá bem, (e dirigindo-se para outro aluno ) ... agora é você, diga o que você fez 
Esse fragmento discursivo evidencia que a professora limita-se a fazer perguntas - estratégia típica do discurso pedagógico, com a intenção de verificar se os alunos haviam realizado a tarefa, sem preocupação com o objeto de sentido, qual seja, o conteúdo do trabalho, e sem atentar para as informações complementares (orais) dos alunos. Não há evidências de intenção, por parte da professora, de fazer uso daquele evento para manter a situação dialógica, ou seja, a manutenção da temática, procurando incorporar o conhecimento do aluno, objeto de estudo pretendido. $\mathrm{Na}$ terminologia de Bakhtin pode se dizer que o professor não realiza a troca verbal que implicaria a negociação de sentido e incorporação da palavra do outro a seu discurso e a seu sistema de explicação. A análise dos dados sugere ainda que a estratégia discursiva utilizada pela professora nem mesmo confirma informações extras solicitadas pelo aluno, conforme se pode verificar nas linhas 3,5,6 e 7. Por outro lado, embora a estratégia de pergunta-resposta necessariamente instaure 0 outro, possibilitando a alternância dos falantes, percebe-se que este fato por si só, como diz Bahktin, não caracteriza a presença de relações dialógicas, relações de sentido que extrapolam as relações expressas pela forma lingüística. Isto é, não há réplicas, nem tréplicas, a troca verbal não se processa na sua forma integral, possivelmente porque não há negociação de sentidos, e porque o "tema" estabelecido no início do evento o tenha sido apenas de maneira formal. Tanto é assim que do ponto de vista pedagógico, a estratégia discursiva do professor pouco contribuiu para fazer avançar o conhecimento do aluno, mesmo quando este cria condições para tanto, como nos exemplos acima já mencionados. A análise deste evento indica que provavelmente a atividade de verificação de tarefas não é compreendida pela professora como uma atividade que diga respeito a um momento de apropriação/transmissão do conhecimento, no bojo do processo ensino-aprendizagem. $E$, neste sentido, poderíamos afirmar que seu discurso, enquanto instrumento de mediação, apresenta-se bastante limitado, manifestando aquilo que, no dizer de Habermas, configuraria uma razão unicamente instrumental. 


\section{Evento 2}

No evento 2, a atividade central é a avaliação da aprendizagem do conceito "tempo"; para tanto a professora estabelece um grupo de discussão, nos moldes clássicos alunos sentados em círculos.

9 Profa. O que você entendeu do que foi apresentado?

10 Aluno: (fica em silêncio durante algum tempo e responde)... a Colonização de Natal

11 Profa. Muito bem... como era aqui antes do homem branco chegar...

12 Várias vozes: ...viviam os indios

13 Aluno: eles viviam numa boa tia..

14 Aluno: ... viviam numa toca

15 Aluno:(outro corrigindo o anterior) toca não oca

16 Profa. Que fizeram os homens brancos?

17 Aluno: matar os animais e comia... comia plantas

18 Prof. Com a chegada dos portugueses o que aconteceu?

19 Aluno: ... botaram os indios para trabalhar... fizeram aliança...

20 Aluno:... para tomar as terras... para colonizar... ter lucro

21 Aluno: ... para tirar Pau-Brasil

22 Profa: O que é colonizar?

23 Aluno:... é construir casas de comercio, casas. ... isto aqui já foi colonizado

24 Profa. Aconteceu alguma transformação com a chegada do europeu?

25 Aluno: aqui era diferente de hoje, .. tinha muitas plantações ...

Percebe-se que, também neste evento, a professora faz uso do par pergunta-resposta como estratégia discursiva privilegiada, embora a estrutura formal apresente-se diferente daquela utilizada no evento anterior. Desta vez, a professora solicita ao aluno uma resposta sob forma de definição visando a investigar o domínio que estes têm sobre os conceitos anteriormente estudados, fazendo uso da estrutura clássica da pergunta, como se pode perceber nas linhas $9,16,18,22$. O processo de instauração das relações dialógicas é semelhante ao primeiro evento, com estabelecimento do tema pela professora e instauração do outro através do mecanismo da alternância. Contudo a análise dos fragmentos de texto indicam que, da mesma forma que no evento 1 , a preocupação com a realização da tarefa sobrepõe-se à instauração e realização do diálogo em suas condições plenas. Por exemplo, 
na linha 15, um aluno dirige-se ao colega, "corrigindo" sua informação, atuando como elemento de mediação no processo ensino/aprendizagem, fato este que não é levado em consideração pela professora, que não retoma a "fala" daquele aluno, perdendo a oportunidade de manter a cadeia dialógica. Mais uma vez, nos parece que a tarefa de verificação de aprendizagem apresenta-se à professora como algo não incorporado ao processo ensino/aprendizagem. As perguntas dirigidas aos alunos surgem como possivel aplicação de um planejamento anterior, limitando-se a professora a proferi-las, sem levar em consideração as respostas dos alunos, nem a tentativa destes de contribuir para o tema, mesmo quando as respostas dos alunos, do ponto de vista do conteúdo, possam ser consideradas satisfatórias.

\section{Evento 3}

O evento 3 diz respeito à introdução das noções de tempo presente e passado em associação com as tipologias textuais da descrição e da narração

26 Profa. Eu pedi para que vocês contassem a história da dramatização não foi? Assim como a gente tivesse assistido um filme e depois contasse...

27 Aluno: tia .. já ontem nos Trapalhões tinha animais...

28 Profa.... eu peguei a história escrita por um aluno e agora vamos arrumar bem direitinho...narrar é contar como aconteceu a história e descrever é como é

29 Aluno: ...é dizer como ela é tia?

30 Profa.: ...para descrever os animais ... o que você fez.... o que você falou do animal?

31 Aluno: (fica em silêncio)

32 Profa: ... que animal você descreveu?

33 Aluno : o cachorro peludo

34 Outro aluno(complementando a questão da professora): como é ele... nasceu de que ...

Nesse evento, as estratégias discursivas utilizadas pela professora não obedecem tão rigidamente ao padrão estabelecido nos eventos anteriores. As perguntas, algumas vezes, são abertas e a professora solicita complementação de seu enunciado, dirigindo-se mais de uma vez ao mesmo aluno, como se pode verificar nas linhas 30, 31, 32 e 33. Mesmo 
assim, a professora continua a ignorar algumas respostas dos alunos, ou a tentativa destes de estabelecer um diálogo pleno, que viria contribuir para o conhecimento do objeto do sentido no caso, a descrição -, como evidenciam as linhas 27 e 29 do exemplo acima.

De nosso ponto de vista, possivelmente a ligeira mudança de estratégias discursivas do professor prende-se ao fato de que este evento representa uma situação típica de sala de aula, na qual cabe à professora o papel de "ensinar um novo conteúdo" , o cerne do processo ensino/aprendizagem, passando, neste processo, suas estratégias discursivas a funcionar como instrumento mediador. As perguntas dirigidas aos alunos, ainda que em sua estrutura formal semelhantes àquelas utilizadas nos eventos anteriores, têm uma outra finalidade, qual seja, a de estimular o aluno, como se pode perceber nos exemplos 30 e 32. No entanto, isto não se verifica durante toda a aula; em alguns momentos, a professora retoma as estratégias utilizadas anteriormente, impedindo que os enunciados, quer sejam os seus, quer sejam os dos alunos, deixem de funcionar como respostas que dão continuidade à cadeia discursiva, como se pode observar nas linhas 35 a 42 . Nestes exemplos, a professora, na tentativa de levar os alunos a refletir e chegar às respostas sozinhos, perde-se na realização da tarefa.

35 Profa: Contar a história é a mesma coisa que fazer descrição?

36 Aluno: ... é

37 Outro aluno : não é tia... porque às vezes a história a gente conta e a narração só escreve..

38 Profa: ... olhe para mim e descreva... sou alta?

39 Aluno: baixa

40 Outro aluno: óculos

41 Outro : cabelo preto e branco

42 Profa. Tanto a gente fala descrevendo como narrando... então o que é diferente entre a narração e a descrição?

Com relação às vozes presentes no discurso da professora, inicialmente percebemos que havia insuficiência de dados, quantitativamente, de forma a permitir uma análise mais detalhada. Isto é, do ponto de vista dos procedimentos metodológicos, percebemos que os dados necessários a este 
tipo de análise, de forma a permitir alguma generalização, necessitam de ser coletados em um período mais longo, possivelmente um bimestre escolar.

De qualquer forma, os dados de que dispúnhamos nos permitem afirmar que os fragmentos discursivos analisados apresentam um misto de gêneros de discurso primário e secundário, para usar a terminologia de Bakhtin. Por exemplo, na linha 28 , a professora inicia com "...eu peguei a história escrita por um aluno e agora vamos arrumar bem direitinho..." fazendo uso da linguagem informal, com um léxico próximo daquele utilizado no discurso do cotidiano, para em seguida esboçar uma definição do que seria "narração" e "descrição", como se pode observar no fragmento a seguir, "...narrar é contar como aconteceu a história e descrever é como é...”, em uma tentativa de aproximar-se do gênero do discurso secundário, característica do conhecimento científico. O mesmo pode se perceber nas linhas 22, quando a professora solicita ao aluno a definição do que seja colonização "...O que é colonizar?...", e nas linhas 35, e 42 “...Contar a história é a mesma coisa que fazer descrição?...", "...Tanto a gente fala descrevendo como narrando... então o que é diferente entre a narração e a descrição?...", quando mais uma vez investe na tentativa de formular definições.

Em sintese, em relação às vozes presentes no discurso do professor, podemos dizer que há uma tentativa de introdução do gênero de discurso secundário, gênero este cuja manifestação discursiva está mais próxima do conhecimento científico do que do senso comum, por fazer uso do signo verbal em sua função de mediação semiótica no processo de formação de conceitos (Vygotsky, 1934), que implica definições, classificações, categorizações. No entanto, observamos também, embora este não fosse nosso objetivo, que as definições apresentadas pela professora, por exemplo, para distinguir "descrição e narração" são incompletas e insuficientes para que possam ser consideradas definições.

\section{ALGUMAS CONSIDERAÇÕES}

A análise discursiva evidencia que o discurso do professor está ainda longe de ser aquele que possibilita o 
estabelecimento de um diálogo real, em que a instauração do outro leve a uma negociação de sentidos, a perguntas que possibilitem a réplica e, mesmo quando esta ocorre, que se proceda à tréplica. Em outras palavras, a análise sugere que, embora apresentem marcas formais explícitas, características do discurso pedagógico, a situação de interação de sala de aula não permitiu, com exceção de alguns momentos do evento 3 , que os enunciados fluíssem, funcionando como elos na cadeia da comunicação, representando a troca de consciências, os vínculos entre interlocutores, possibilitando a efetivação daquilo que Bahktin chamou de "compreensão responsiva ativa", essencial para a realização do processo dialógico. Nesse sentido os nossos dados diferem daqueles obtidos por Smolka e se aproximam mais daqueles de Gabbiani. Talvez, no experimento relatado por Smolka, a prática alternativa dos professores deva-se a variáveis outras como, por exemplo, o fato de que aquela escola passava por um processo de assessoramento pedagógico.

De qualquer forma, essas observações sobre a "alternância de sujeitos" e aquelas sobre "as vozes" nos permitem ressaltar a necessidade de se atentar para a formação dos profissionais de ensino, tanto no que diz respeito ao conteúdo espécífico de suas áreas de conhecimento como à relação entre estratégias discursivas e práticas pedagógicas. Embora tenhamos claro que, nos eventos analisados, dificilmente poderíamos classificar de autoritários, o discurso ou a prática da professora, podemos, no entanto, afirmar que a forma de utilização de estratégias discursivas, enquanto instrumento mediador na realização das atividades didáticopedagógicas, de longe propiciou o surgimento das relações dialógicas que possibilitariam a negociação dos sentidos e a incorporação de conhecimentos dos alunos àquele do sistema escolar e, conseqüentemente, sua transformação em conhecimento científico. Há muito ainda a ser feito para que possamos classificar estas relações de dialógicas. E é nesse sentido que concordamos com Moita Lopes (1996), quando este considera que, apesar do encontro interacional em sala de aula ser caracterizado como um "encontro ensino/aprendizagem", para que este seja socialmente orientado e justificável é 
necessário que se instaurem interlocutores discursivos participantes.

E sobre este tema, Kohl (1995) afirma que, nas questões da prática pedagógica e da atuação docente, a relação entre desenvolvimento e aprendizagem deve ser vista como um processo no qual é necessário que se postulem relações interpessoais. No caso específico do discurso pedagógico, por exemplo, podemos dizer que este papel pode ser desempenhado pelo professor, ou pelo livro didático, ou mesmo por um colega de classe. Nossos eventos apontam que há pouca evidência do papel do professor naquela direção, mesmo quando algum aluno "ensaiara" a realização de tal papel.

Por outro lado, não é demais lembrar, especialmente no campo da formação de professores, a necessidade da aproximação da prática pedagógica com o conhecimento científico; para tanto, pensamos ser necessário, no campo das ciências humanas, superar a visão dicotômica que opõe as pesquisas sobre o papel do conhecimento teórico na formação de professores àqueles que consideram como única fonte de conhecimento as pesquisas das práticas concretas do professor em sala de aula.

$E$, nesse sentido, é que reafirmamos nossa concordância com as abordagens que consideram a importância do conhecimento sistematizado como fundamental na superação do senso comum, considerando que a escola é o lugar privilegiado da socialização do saber, na medida em que divulga e socializa o saber nela e por ela produzido. Pensando juntamente com Bakhtin (1981), que a produção do conhecimento se dá a partir das (e pelas) vozes dos outros, entendemos ser necessário que a escola assuma o importante papel de tornar públicos os conhecimentos privados das comunidades científicas, inter-relacionando-os com os conhecimentos dos educandos, com vistas à construção de um novo conhecimento, que leva em consideração o cotidiano dos próprios sujeitos na aprendizagem . 


\section{REFERÊNCIAS BIBLIOGRÁFICAS}

BAHKTIN, M. Marxismo e Filosofia da Linguagem.São Paulo: Hucitec, 1969. (Original, 1929).

BAHKTIN, M. Estética da Criação Verbal. São Paulo: Martins Fontes, 1992. (Original, 1952).

BAHKTIN, M. Problemas da Poética de Dostoiévsky. Rio de Janeiro: Forense Universitária, 1981. (Original, 1963).

BERNSTEIN. B. The structuring of pedagogic discourse. Class, Codes and Control. London: Routledge, 1990. v. IV.

BRAIT, B. O processo interacional. In: D.Preti (Org.). Análise de Textos Orais. Faculdade de Filosofia,Letras e Ciências Humanas da Universidade de São Paulo, 1995.

BUNGE, M. La investigacion cientifica su estrategia y su filosofia. Barcelona: Ed. Ariel, 1973.

COLE, M. Desenvolvimento cognitivo e escolarização formal: a evidência da pesquisa transcultural. In: L.C.Moll (Org.). Vygotsky e a Educação. Porto Alegre: Artes Médicas, 1996.

FOURQUIN, J.C. Escola e Cultura. Porto Alegre: Artes Médicas, 1993.

GABBIANI, B. Estratégias de interaccion en el aula: implicancias pedagógicas de la triada pergunta-respuestaevaluacion. Trabalhos de Lingüística Aplicada, n. 18, p. 29-38, 1991.

HABERMAS, J. Teoria de la acción comunicativa. Madrid: Taurus, 1987.

KLEIMAN, A. Introdução e um início: a pesquisa sobre interação e aprendizagem. Trabalhos de Lingüística Aplicada, n.18, p.5-14, 1991.

KLEIMAN, A. Cooperation and control in teaching: the evidence of classsroom questions. D.E.L.T.A., v.8, n.2, p.187-204, 1992. 
KOHL, M. Pensar a Educação : contribuições de Vygotsky. São Paulo: Ática, 1995.

LEFEBVRE, $H$. Problemas atuais do marxismo. Portugal, Editorial Fronteira, 1977 (trad. do orig. francês, 1970).

MOITA LOPES, L.P. da. Co-construção do discurso em sala de aula: alinhamento a contextos gerados pela professora. Trabalho apresentado no $\mathrm{V}$ International Pragmatics Conference. México, 1996 (no prelo).

NAGEL, E. La estrutura de la ciencia. Buenos Aires: Paidós, 1974.

OLIVEIRA, M.B.F. de. A concepção dialógica da linguagem: uma contribuição ao estudo da relação linguagem $e$ cognição. Estudos de Psicologia. Natal: UFRN, Edufrn. v.1, n.2, p.227-252, 1996. ISSN 1413-294X.

SMOLKA, A L.B. A prática discursiva na sala de aula: uma perspectiva teórica e um esboço de análise. Caderno Cedes. Campinas: Papirus, 24, 1991a .

SMOLKA, A L.B. Múltipla vozes na sala de aula: aspectos da construção coletiva do conhecimento na escola. Trabalhos de Lingüística Aplicada, n.18, p.15-28,1991b.

VYGOTSKY, L.V. Pensamento e Linguagem. Lisboa: Antídoto, 1979. (Original publicado em 1934). 